\title{
Early responses to manganese (Mn) excess and its relation to antioxidant performance and organic acid exudation in barley cultivars
}

Rayen Millaleo $^{1 *}$, Maria Rao², Elizabeth Ulloa-Inostroza ${ }^{3}$, Paola Duran ${ }^{1,5}$, Maria de La Luz Mora ${ }^{1,4}$

${ }^{1}$ Center of Plant, Soil Interaction, and Natural Resources Biotechnology, Scientific and Technological Bioresource Nucleus (BIOREN), Universidad de La Frontera, Casilla 54-D, Temuco, Chile. ${ }^{2}$ Department of Agriculture, University of Naples Federico II, Napoli, Italy, ${ }^{3}$ Universidad de Aysén, Coyhaique-Chile. ${ }^{4}$ Departamento de Ciencias Químicas y Recursos Naturales, Facultad de Ingeniería, Ciencias y Administración, Universidad de La Frontera, Temuco-Chile. ${ }^{5}$ Biocontrol Research Laboratory, Universidad de La Frontera, Temuco-Chile*Corresponding author: rayen.millaleo@ufrontera.cl

\begin{abstract}
Manganese (Mn) is an essential micronutrient for plants, and is necessary for biochemical and physiological processes. The objective of this research was to determine the early responses to $\mathrm{Mn}$ excess and its relation to antioxidant performance mechanisms and organic acid exudation in commercial barley cultivars. We determined early responses to Mn excess in four barley cultivars (Barke, Tatoo, Scarlett, Sebastian), which were subjected to increasing Mn concentrations (2.4-150-350-750-1500 $\mu \mathrm{M} \mathrm{Mn}$ ), $\mathrm{pH} 4.8$, under nutrient solution during seven days. Results showed that plant growth parameters: biomass, length and relative growth rate (RGR) were negatively altered with the higher Mn treatments. Antioxidant performance such as antioxidant activity (AA) and antioxidant enzymes such as superoxidase dismutase (SOD) were activated in presence of excess Mn. Oxalate was the major organic acid roots exudate, and the cultivar Sebastian had the highest oxalate exudation. In conclusion, Tatoo and Sebastian are proposed as the most Mn tolerant cultivars given that the biomass parameters were not affected by increasing Mn doses, showing major oxalate exudation. It is suggested that the mechanisms associated to $\mathrm{Mn}$ alleviation could be attributed to SOD, AA and organic acid production, mainly oxalate, in tolerant cultivars (Sebastian, Tatoo) together to significant decrease of total phenols (TP) in shoot of sensitive cultivars (Barke and Scarlett). Non-enzymatic barriers were not related to early responses, and an enzymatic barrier and oxalate exudation were considered as early indicators of Mn stress, projecting that the tolerance of Mn-tolerant cultivars could increase under field conditions.
\end{abstract}

Keywords: Manganese excess, barley, organic anion exudation, antioxidant system. 


\section{Introduction}

Manganese is an essential micronutrient for plants, as it is necessary for biochemical and physiological processes, specifically involved in photosynthesis, respiration, enzyme and protein synthesis (Marschner and Marschner., 2012; Bityutskii, et al., 2017; Shao et al., 2017). However, Mn excess can induce phytotoxicity due to increased Mn solubility in an acidic soil solution $(\mathrm{pH}<5.5)$, increasing Mn uptake into the cell roots, mainly in cationic $\mathrm{Mn}^{2+}$ form (Kopittke et al., 2013; Blamey et al., 2015). As result, visual shoot symptoms such as necrotic root tissues and brown necrotic spots have been observed in crops subjected to high doses of $\mathrm{Mn}$. These are the first symptoms of $\mathrm{Mn}$ toxicity due to chlorophyll destruction and the oxidation of phenolic compounds, respectively (Demirevska-Kepova et al., 2004; St.Clair and Lynch., 2005; Rosas et al., 2007; Millaleo et al., 2010; Santos et al., 2017). Accordingly, significant reductions of shoot biomass because of increased Mn doses are shown in plants, as consequence of a reduction in $\mathrm{CO}_{2}$ assimilation and stomatal conductance (Santos et al., 2017).

Excess of Mn causes imbalances in the production of reactive oxygen species (ROS), exacerbating oxidative stress through lipid peroxidation (LP) of membranes in crops such as barley, clover, soybean and perennial ryegrass (Demirevska-Kepova et al., 2004; Rosas et al., 2007; Mora et al., 2009; Reyes-Díaz et al., 2017; Santos et al., 2017). To counteract Mn excess induced oxidative stress, plants are capable of improving antioxidant mechanisms such as enzymatic and non-enzymatic compounds. Non-enzymatic compounds such as phenols are able to donate electrons or generate protons which are effective ROS scavenging compounds against metal stresses (Ulloa-Inostroza et al., 2017). Likewise, antioxidant enzymes such as superoxide dismutase (SOD) and guaiacol peroxidase (POD) increase their activity under Mn excess, raising values of antioxidants that are correlated with a higher ROS detoxification in plants (Shi et al., 2005, 2006; Mora et al., 2009; Gangwar et al., 2010; Ribera et al., 2013; Santos et al., 2017). In contrast, other studies show that the antioxidant system decreases its activity due to the effects of Mn (Li et al., 2012). This occurs when plants are able to counteract the toxic effects of excess $\mathrm{Mn}$, therefore decreasing antioxidant enzyme activity such as SOD in cultivars like cucumber $(\mathrm{Cu}$ cumis sativus) (Shi et al., 2006), perennial ryegrass (Lolium perenne) (Mora et al., 2009) and pea (Pisum sativum) (Gangwar et al., 2010). These contrasting antioxidant responses when facing excess $\mathrm{Mn}$ are directly influenced by $\mathrm{Mn}$ resistance and sensitivity mechanisms in plants (Millaleo et al., 2010).

Cereal crops are some of the most cultivated in southern Chile with a crop area of over 350,000 hectares (ODEPA, 2018). Given the high acidity levels of Andisol, which can lead to Mn phytotoxicity, combined with the limited information available about Mn tolerance in commercial cereal cultivars, the objective of this study was to determine the early responses to Mn excess and its relation to antioxidant performance mechanisms and organic acid exudation in commercial barley cultivars.

\section{Materials and Methods}

\subsection{Plant material and Mn treatments}

Barley (Hordeum vulgare L.) seed from four cultivars (Barke, Tatoo, Scarlett, Sebastian) were germinated on filter paper moistened with $10 \mathrm{~mL}$ of deionized water $(<1 \mu \mathrm{S})$ for seven days. After germination, 10 seedlings per pot $(200 \mathrm{~mL})$ were transferred containing hydroponic system (Taylor and Foy, 1985) composed of: $1270 \mu \mathrm{M} \mathrm{Ca}\left(\mathrm{NO}_{3}\right)_{2}, 650 \mu \mathrm{M} \mathrm{KNO}_{3}, 120 \mu \mathrm{M} \mathrm{MgSO}_{4}$, 
$100 \mu \mathrm{M} \mathrm{K}_{2} \mathrm{HPO}_{4}, 2.4 \mu \mathrm{M} \mathrm{MnSO}_{4}, 1000 \mu \mathrm{M} \mathrm{NH}-$ ${ }_{4} \mathrm{NO}_{3}, 6.6 \mu \mathrm{M} \mathrm{Na}_{2} \mathrm{~B}_{4} \mathrm{O}_{7}, 150 \mu \mathrm{M} \mathrm{Mg}\left(\mathrm{NO}_{3}\right)_{2}, 0.1 \mu \mathrm{M}$ $\left(\mathrm{NH}_{4}\right)_{6} \mathrm{Mo}_{7} \mathrm{O}_{24}, 0.6 \mu \mathrm{M} \mathrm{ZnSO}_{4}, 0.2 \mu \mathrm{M} \mathrm{CuSO}_{4}, 17.9$ $\mu \mathrm{M}$ Fe- EDTA and $46 \mu \mathrm{M} \mathrm{NaCl}$. Experimental design was completely randomized. Four replicates per treatment were used, with a total of 80 barley seedlings and 10 plants per pot. Barley cultivars were subjected to control Mn concentrations using plants subjected to $2.4 \mu \mathrm{M} \mathrm{MnCl}_{2}$ (Taylor and Foy nutrient solution) and increasing Mn concentrations of 150, 350, 750 and $1500 \mu \mathrm{M}$ Mn. These Mn concentrations were added as $\mathrm{MnCl}_{2} \times 4 \mathrm{H}_{2} \mathrm{O}$ at the beginning of the assays. Control plants were exposed to $2.4 \mu \mathrm{M} \mathrm{Mn}$, as is the optimal dose of Mn for grass species (Rosas et al., 2007). After an acclimation period of seven days, plants were subjected to Mn treatments during seven days. Later, seedlings were allocated at hydroponic a nutrient solution at $\mathrm{pH} 4.8$, which was renewed every 2 days. A pH adjustment was performed daily. Solutions were aerated continuously with an aquarium pump and changed before and after the start of treatments.

The acclimation period was 7 days at semi controlled conditions with a $16 / 8 \mathrm{~h}$ photoperiod at $25 / 16{ }^{\circ} \mathrm{C}$ (day/night) and relative humidity range of $60-70 \%$ under greenhouse conditions. The study was carried out at the Scientific and Technological Bioresource Nucleus (BIOREN) at the Universidad de La Frontera, Temuco, Chile ( $\left.38^{\circ} 45^{\prime} \mathrm{S}, 72^{\circ} .40^{\prime} \mathrm{W}\right)$.

Finally, roots and shoots were carefully separated and dried at $65{ }^{\circ} \mathrm{C}$ during $48 \mathrm{~h}$ for subsequent chemical analysis and growth determinations. Plant material was stored at $-80^{\circ} \mathrm{C}$ for later biochemical analysis.

\subsection{Plant growth determinations}

Relative growth rate (RGR), total biomass and length: At the beginning of the Mn treatments, plant samples (separated in shoots and roots) from each barley cultivar were dried and weighed to determine dry weight
(W1) at day $0(\mathrm{t} 1)$. At harvest time $(\mathrm{t} 2=7 \mathrm{~d})$, plant material was also collected for dry weight measurements (W2). Dry weight data were used to determine mean relative growth rate (RGR), defined as an increase of dry weight per unit of biomass and per day [ $\mathrm{g} \mathrm{DW} \mathrm{g}^{-1}$ day $^{-1}$ ] using the formula from previous studies (Fernando et al., 2009):

$$
R G R=\frac{\ln \mathrm{W} 2-\ln \mathrm{W} 1}{\mathrm{t} 2-\mathrm{t} 1}
$$

Where:

$\ln \mathrm{W} 2=$ media of $\ln$ transformed plant weight at the end of the experiment (day 7, t2)

$\ln \mathrm{W} 1=$ media of $\ln$ transformed plant weight at the start of the experiment (day $0, \mathrm{t} 1$ ).

Biomass of shoots and roots was calculated based in dry weight (mg) at the end of each experiment (t2). Lengths of shoots and roots $(\mathrm{cm})$ were taken from the barley plants to measure the last grown leaf (shoot) and last grown root.

\subsection{Manganese content}

Plant material was reduced in a muffle furnace at $500{ }^{\circ} \mathrm{C}$ for $8 \mathrm{~h}$ and treated with $2 \mathrm{M}$ hydrochloric acid ( $\mathrm{HCl})$. Mn was quantified using a simultaneous multielement atomic absorption spectrophotometer (Model 969; Unicam, Cambridge, UK) according to (Sadzawka et al. 2007). To obtain Mn content, values of Mn concentrations were multiplied by the dry matter from the plant material

\subsection{Lipid peroxidation}

The level of lipid peroxidation (LP) was assessed in fresh samples of roots and shoots from barley by monitoring the thiobarbituric acid reacting substances (TBARS) as an index of oxidative damage to the plant cells. Absorbance was measured at 532, 600 and 440 
$\mathrm{nm}$ in order to correct the interference generated by TBARS-sugar complexes according to the modified method by Du and Bramlage (1992). This method determines the occurrence of malondialdehyde (MDA) as a secondary by product of the polyunsaturated fatty acid oxidation that can react with thiobarbituric acid (TBA) (Hodges et al., 1999). The unit for LP was determined as equivalents of malondialdehyde (MDA) content (nmol g-1 FW).

\subsection{Antioxidant activity}

Samples were homogenized by applying ethanol $(80 \% \mathrm{v} / \mathrm{v})$ and then centrifuged at $13000 \mathrm{rpm}$ at $4{ }^{\circ} \mathrm{C}$ for $10 \mathrm{~min}$. Supernatant (extract) was separated and stored at $-20^{\circ} \mathrm{C}$.

\subsubsection{Total Antioxidant Activity (AA)}

The AA was determined in shoots and roots using 2.2-diphenyl-1-picrylhydrazyl (DPPH•) stable free radical according to Chinnici et al., (2004) with minor modifications. A $250 \mu \mathrm{L}$ aliquot of extract was mixed with $750 \mu \mathrm{L}$ DPPH ethanolic solution $(250 \mu \mathrm{M})$ in darkness for $30 \mathrm{~min}$ at room temperature. Later, samples were mixed and measured at $517 \mathrm{~nm}$ in a multimode microplate reader (SynergyTM HT, BIOTEK). Values were expressed as Trolox equivalents $\left[\mu \mathrm{M} \mathrm{g}^{-1}\right.$ fresh weight (FW)] using standard curves.

\subsubsection{Total phenols}

Total phenols (TP) was determined by the Folin-Ciocalteau reagent, according to Slinkard and Singleton (1977). Aliquot extracts of $50 \mu \mathrm{L}$ were mixed with $550 \mu \mathrm{L}$ of deionized water and $100 \mu \mathrm{L}$ of the FolinCiocalteau reagent. After 5 min, $300 \mu \mathrm{L}$ of $\mathrm{Na}_{2} \mathrm{CO}_{3}$ (7\%) was applied and mixed again. Mix extract was incubated for $10 \mathrm{~min}$ and measured at $760 \mathrm{~nm}$ using a multimode microplate reader (SynergyTM HT, BIOTEK). Results were expressed as micrograms of gallic acid equivalent per gram of fresh weight ( $\mu \mathrm{g}$ GAE $\mathrm{g}^{-1} \mathrm{FW}$ ).

\subsubsection{Antioxidant enzymes activity}

For antioxidant enzyme extraction, samples of fresh shoot material were frozen in liquid nitrogen and stored at $-80^{\circ} \mathrm{C}$ before extraction. Later, subsamples were ground in liquid nitrogen with $0.1 \mathrm{M}$ potassium phosphate buffer $\left(\mathrm{K}_{2} \mathrm{HPO}_{4}-\mathrm{KH}_{2} \mathrm{PO}_{4}\right)$ at $\mathrm{pH} 7.0$, then centrifuged at $13000 \mathrm{rpm}$ at $4{ }^{\circ} \mathrm{C}$ during $15 \mathrm{~min}$. The supernatant was collected and stored for subsequent enzymatic analysis. All enzymatic activities were expressed on the basis of total protein, according to Bradford (1976).

i) Superoxide dismutase (SOD) activity. The SOD activity was assayed by monitoring the photochemical inhibition of nitroblue tetrazolium (NBT) according to Giannopolitis and Ries (1977) with minor modifications (Mora et al., 2009). Summarizing, $20 \mu \mathrm{L}$ of crude extracts were exposed to a reaction mixture containing $0.1 \mathrm{M}$ potassium phosphate buffer $\mathrm{pH}$ 7.0, $10 \mathrm{mM}$ ethylenediaminetetraacetic acid (EDTA), 260 $\mathrm{mM}$ methionine and $4200 \mu \mathrm{M}$ NBT. The reaction started by adding $130 \mu \mathrm{M}$ riboflavin. Sample mixtures were illuminated for $15 \mathrm{~min}$ and blanks were kept in darkness during course of the assay, at the same time. Absorbance was measured at $560 \mathrm{~nm}$ on a multimode microplate reader (Synergy TM HT, BIOTEK). One unit of SOD activity $\left(\mathrm{U} \mathrm{g} \mathrm{g}^{-1}\right)$ was defined as the amount of enzyme required to cause $50 \%$ inhibition of the NBT reduction.

ii) Guaiacol peroxidase (POD) activity. The enzymatic activity consisted of measuring the formation of tetraguaiacol at $470 \mathrm{~nm}$ during $60 \mathrm{~s}$, according to Mora et al., (2009). Sample extract $(2 \mu \mathrm{L})$ was added to the reaction mixture, which contained $1 \mathrm{~mL}$ 
of extraction buffer, $5 \mu \mathrm{L}$ of $\mathrm{H}_{2} \mathrm{O}_{2}(30 \% \mathrm{v} / \mathrm{v})$ and 5 $\mu \mathrm{L}$ of guaiacol. Over time, absorbance was measured on a multimode microplate reader (Synergy TM HT, BIOTEK).

\subsection{Determination of organic acids from root exu-} dates

Exudates were collected using the methodology described by Rosas et al., (2007) with minor modifications (Meier et al., 2012). Generally, entire plants were extracted and roots were washed and rinsed with deionized water. Later, samples were placed in $50 \mathrm{~mL}$ of HPLC water with aeration during $2 \mathrm{~h}$, to avoid microbial degradation of organic acids (Jones and Darrah, 1994). For anion organic acid exudation, samples were taken from the control $(2.4 \mu \mathrm{M} \mathrm{Mn})$, and the highest Mn dose (1500 $\mu \mathrm{M}$ Mn). Oxalate, citrate, malate and succinate concentration in exudates were evaluated.

Samples were lyophilized, resuspended in 800-1000 $\mu \mathrm{L}$ of HPLC water, filtered $(0.22 \mu \mathrm{m})$ and analyzed by HPLC chromatography system (Merck-Hitachi, Primaide 1000 series modules) with a UV-visible detector and diode array detector. Analysis of HPLC was conducted on a $250 \times 4.6 \mathrm{~mm}$ reverse phase column (Purospher STAR 120 RP-18, $5 \mu \mathrm{m}$ particle size, Merck, Darmstadt, Germany). The mobile phase was $\mathrm{H}_{2} \mathrm{O}-\mathrm{CH}_{3} \mathrm{OH}$ with orthophosphoric acid $(200 \mathrm{mM}$, at
pH 2.1) buffer. The gradient started with $80 / 20 \mathrm{H}_{2} \mathrm{O}-$ $\mathrm{CH}_{3} \mathrm{OH}(\mathrm{v} / \mathrm{v})$ during $2.5 \mathrm{~min}$ and then $77 / 23 \mathrm{H}_{2} \mathrm{O}-$ $\mathrm{CH}_{3} \mathrm{OH}(\mathrm{v} / \mathrm{v})$ during 2.6-4.7 min and returning to $80 / 20 \mathrm{H}_{2} \mathrm{O}-\mathrm{CH}_{3} \mathrm{OH}(\mathrm{v} / \mathrm{v})$ to complete $7 \mathrm{~min}$ total. The flow rate used was $1 \mathrm{~mL} \mathrm{m^{-1 }}, 20 \mu \mathrm{L}$ the injection volume and the detection wavelength was $\lambda 210 \mathrm{~nm}$.

\subsection{Statistical analysis}

The presented results are the mean values with standard errors based on 4 replicates, where all data passed the normality and equal variance tests according to Kolmogorov-Smirnov. Differences between treatments and cultivars were carried out by two-way ANOVA. Tukey's test was used to identify means with significant differences $(\mathrm{P} \leq 0.05$ and $\mathrm{P} \leq 0.01)$. The statistical software Sigma Plot 11.0 was used. Furthermore, to group and determine significant differences between samples based on antioxidant activity, productivity and biochemical parameters, data were imported into the PRIMER 7 software (PRIMER-E Ltd, Ivybridge, UK), transformed by a log (Xp1) and normalized. Then, a distance matrix was generated based on Euclidean distances and samples were grouped by hierarchical clustering (group average), then visualized by Principal Component Analysis (PCA). Results of the correlation analysis are given according to their levels of significance as ** and $*$ for $\mathrm{P}<0.01$ and $<$ 0.05 , respectively. 


\section{Results}

\subsection{Plant growth parameters}

Plant shoots belonging to Barke and Scarlett cultivars showed less biomass when major Mn doses were applied, whereas Tatoo showed no difference in biomass with respect to the control. Sebastian cultivars showed a difference in biomass only at in the highest doses of Mn $(1500 \mu \mathrm{M})$. In the roots, only Scarlett cultivars showed less biomass at increasing doses (Table 1).

Table 1. Total biomass, relative growth rate (RGR) and length (shoots and roots) of barley cultivars grown in nutrient solution with increasing $\mathrm{Mn}$ doses at the end of the experiment (7 days). Results are shown as means, with $\mathrm{n}=4$ as standard error $( \pm \mathrm{SE})$. Different lower-case letters indicate statistically significant differences between $\mathrm{Mn}$ treatments for the same cultivar ( $\mathrm{P}<0.05$, Tukey's test).

\begin{tabular}{llllllll}
\hline \hline Cultivar & $\begin{array}{l}\text { Mn treatments } \\
(\mu \mathrm{M})\end{array}$ & \multicolumn{2}{c}{$\begin{array}{c}\text { Biomass } \\
(\mathrm{mg})\end{array}$} & \multicolumn{2}{c}{$\begin{array}{c}\text { RGR } \\
\left(\mathrm{g} \mathrm{DW} \mathrm{g} \mathrm{day}^{-1}\right)\end{array}$} & \multicolumn{2}{c}{$\begin{array}{c}\text { Length } \\
(\mathrm{cm})\end{array}$} \\
& & Shoot & Root & Shoot & Root & Shoot & Root \\
\hline Barke & $\mathrm{C}$ & $243 \pm 2 \mathrm{a}$ & $100 \pm 3 \mathrm{a}$ & $0.102 \pm 0.003 \mathrm{a}$ & $0.046 \pm 0.002 \mathrm{a}$ & $18.6 \pm 0.7 \mathrm{a}$ & $10.3 \pm 0.1 \mathrm{a}$ \\
& 150 & $232 \pm 2 \mathrm{~b}$ & $103 \pm 3 \mathrm{a}$ & $0.099 \pm 0.003 \mathrm{a}$ & $0.047 \pm 0.004 \mathrm{a}$ & $17.9 \pm 0.7 \mathrm{ab}$ & $8.5 \pm 0.2 \mathrm{ab}$ \\
& 350 & $225 \pm 1 \mathrm{c}$ & $94 \pm 2 \mathrm{a}$ & $0.073 \pm 0.004 \mathrm{~b}$ & $0.035 \pm 0.003 \mathrm{a}$ & $18.0 \pm 0.6 \mathrm{ab}$ & $7.9 \pm 0.8 \mathrm{~b}$ \\
& 750 & $222 \pm 1 \mathrm{c}$ & $98 \pm 5 \mathrm{a}$ & $0.037 \pm 0.001 \mathrm{~d}$ & $0.009 \pm 0.001 \mathrm{~b}$ & $16.3 \pm 0.4 \mathrm{~b}$ & $8.3 \pm 0.4 \mathrm{~b}$ \\
& 1500 & $204 \pm 1 \mathrm{~d}$ & $95 \pm 3 \mathrm{a}$ & $0.056 \pm 0.001 \mathrm{c}$ & $0.019 \pm 0.003 \mathrm{~b}$ & $16.2 \pm 0.4 \mathrm{~b}$ & $8.1 \pm 0.4 \mathrm{~b}$ \\
\hline Tatoo & $\mathrm{C}$ & $277 \pm 9 \mathrm{a}$ & $82 \pm 4 \mathrm{a}$ & $0.126 \pm 0.002 \mathrm{a}$ & $0.047 \pm 0.004 \mathrm{a}$ & $20.0 \pm 0.7 \mathrm{a}$ & $10.1 \pm 0.2 \mathrm{a}$ \\
& 150 & $280 \pm 1 \mathrm{a}$ & $86 \pm 3 \mathrm{a}$ & $0.100 \pm 0.001 \mathrm{bc}$ & $0.050 \pm 0.001 \mathrm{a}$ & $18.3 \pm 0.6 \mathrm{ab}$ & $9.7 \pm 0.3 \mathrm{ab}$ \\
& 350 & $272 \pm 3 \mathrm{a}$ & $78 \pm 1 \mathrm{a}$ & $0.105 \pm 0,001 \mathrm{~b}$ & $0.039 \pm 0.003 \mathrm{a}$ & $19.4 \pm 0.6 \mathrm{a}$ & $9.6 \pm 0.2 \mathrm{ab}$ \\
& 750 & $288 \pm 5 \mathrm{a}$ & $82 \pm 1 \mathrm{a}$ & $0.098 \pm 0.002 \mathrm{c}$ & $0.023 \pm 0.004 \mathrm{~b}$ & $19.7 \pm 0.6 \mathrm{a}$ & $9.3 \pm 0.1 \mathrm{ab}$ \\
& 1500 & $286 \pm 1 \mathrm{a}$ & $85 \pm 1 \mathrm{a}$ & $0.095 \pm 0.001 \mathrm{c}$ & $0.018 \pm 0.004 \mathrm{~b}$ & $16.7 \pm 0.4 \mathrm{~b}$ & $8.8 \pm 0.3 \mathrm{~b}$ \\
\hline Scarlett & $\mathrm{C}$ & $284 \pm 5 \mathrm{a}$ & $121 \pm 2 \mathrm{a}$ & $0.128 \pm 0.003 \mathrm{a}$ & $0.113 \pm 0.005 \mathrm{a}$ & $21.6 \pm 0.7 \mathrm{a}$ & $16.8 \pm 0.3 \mathrm{a}$ \\
& 150 & $237 \pm 4 \mathrm{~b}$ & $98 \pm 2 \mathrm{~b}$ & $0.126 \pm 0.003 \mathrm{a}$ & $0.090 \pm 0.007 \mathrm{~b}$ & $22.0 \pm 0.4 \mathrm{a}$ & $14.1 \pm 0.4 \mathrm{~b}$ \\
& 350 & $234 \pm 7 \mathrm{bc}$ & $98 \pm 6 \mathrm{~b}$ & $0.093 \pm 0.001 \mathrm{c}$ & $0.060 \pm 0.002 \mathrm{~cd}$ & $17.3 \pm 0.1 \mathrm{~b}$ & $13.6 \pm 0.8 \mathrm{~b}$ \\
& 750 & $212 \pm 5 \mathrm{~d}$ & $107 \pm 1 \mathrm{ab}$ & $0.110 \pm 0.002 \mathrm{~b}$ & $0.078 \pm 0.003 \mathrm{bc}$ & $18.4 \pm 0.6 \mathrm{~b}$ & $13.0 \pm 0.8 \mathrm{bc}$ \\
& 1500 & $215 \pm 1 \mathrm{~cd}$ & $103 \pm 3 \mathrm{~b}$ & $0.097 \pm 0.004 \mathrm{bc}$ & $0.046 \pm 0.003 \mathrm{~d}$ & $17.4 \pm 0.1 \mathrm{~b}$ & $11.0 \pm 0.2 \mathrm{c}$ \\
\hline Sebastian & $\mathrm{C}$ & $229 \pm 3 \mathrm{a}$ & $112 \pm 1 \mathrm{a}$ & $0.093 \pm 0.003 \mathrm{a}$ & $0.022 \pm 0.003 \mathrm{a}$ & $18.5 \pm 0.3 \mathrm{a}$ & $13.6 \pm 0.4 \mathrm{a}$ \\
& 150 & $217 \pm 7 \mathrm{ab}$ & $112 \pm 4 \mathrm{a}$ & $0.080 \pm 0.005 \mathrm{ab}$ & $0.017 \pm 0.001 \mathrm{a}$ & $18.2 \pm 0.5 \mathrm{a}$ & $14.3 \pm 0.5 \mathrm{a}$ \\
& 350 & $226 \pm 1 \mathrm{ab}$ & $105 \pm 2 \mathrm{a}$ & $0.066 \pm 0.002 \mathrm{~b}$ & $0.014 \pm 0.001 \mathrm{a}$ & $18.2 \pm 0.8 \mathrm{a}$ & $15.3 \pm 0.5 \mathrm{a}$ \\
& 750 & $210 \pm 5 \mathrm{ab}$ & $108 \pm 3 \mathrm{a}$ & $0.071 \pm 0.003 \mathrm{~b}$ & $0.018 \pm 0.003 \mathrm{a}$ & $18.8 \pm 0.5 \mathrm{a}$ & $13.6 \pm 0.8 \mathrm{a}$ \\
& 1500 & $209 \pm 3 \mathrm{~b}$ & $108 \pm 3 \mathrm{a}$ & $0.072 \pm 0.002 \mathrm{~b}$ & $0.016 \pm 0.001 \mathrm{a}$ & $19.0 \pm 0.5 \mathrm{a}$ & $13.5 \pm 0.6 \mathrm{a}$ \\
\hline
\end{tabular}

Regarding biomass increase in comparison to the start of the experiment (RGR), all cultivars showed less biomass increase at elevated doses in the shoots. Thus, at the highest Mn doses, Barke showed the highest RGR reduction with respect to control (45\%), Tatoo and Scarlett had a 24\% RGR reduction and Sebastian 23\%. In roots, a similar tendency was observed. Only Sebastian did not show significant differences in root RGR during all Mn doses. RGR reduction was $59 \%$ in Barke, $62 \%$ in Tatoo, $59 \%$ in Scarlett and $27 \%$ in Sebastian (Table 1).

A reduction in shoot lengths was observed in all barley cultivars with the increasing Mn treatments (Table 1). The Sebastian cultivar was the only one which did not show significant differences in shoot length when Mn was applied, in relation to the control. 
In the roots, a similar tendency was observed in which Sebastian remained stable, showing no differences in either tissues.

\subsection{Manganese content}

The Mn content in the barley cultivars increased proportionally with the applied Mn treatments, being greater in roots than in shoots for all cultivars (Figure 1). Scarlett showed major and significant values of $\mathrm{Mn}$ content in roots with the higher $\mathrm{Mn}$ treatments (750 and $1500 \mu \mathrm{M} \mathrm{Mn}$ ), compared with the other barley cultivars.

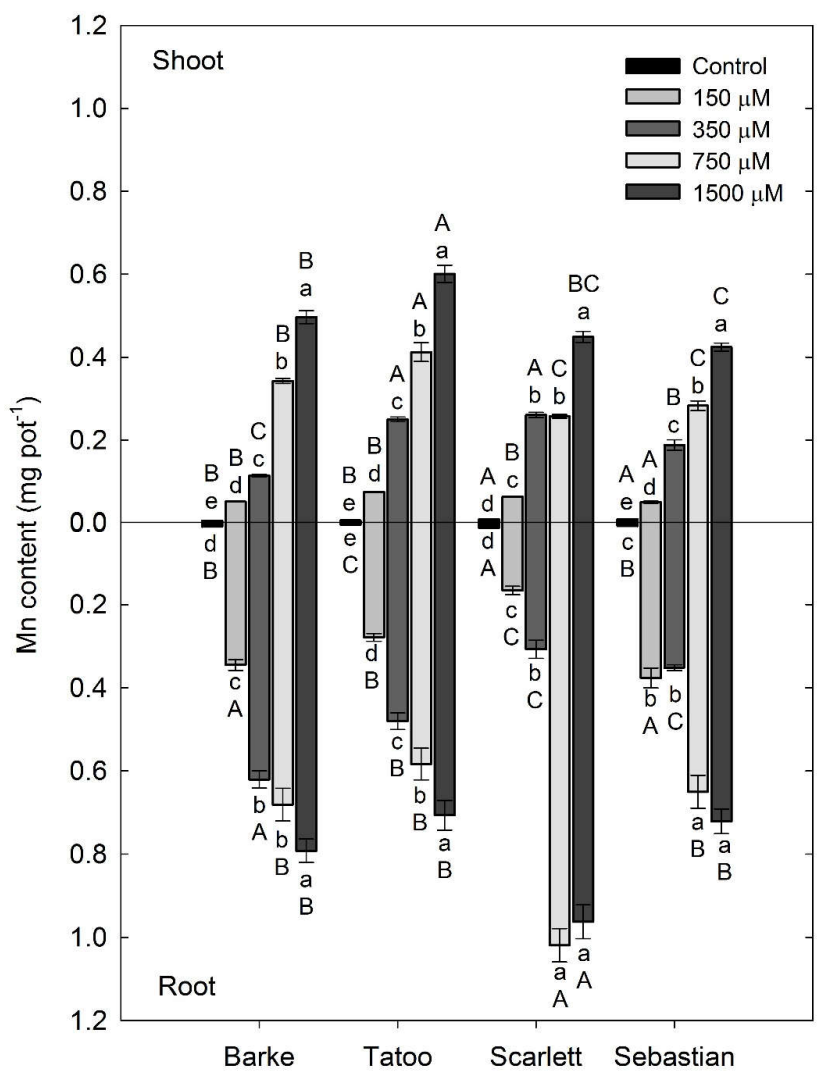

Figure 1. Mn content (mg pot $\left.{ }^{-1}\right)$ of shoots and roots of barley cultivars grown in the nutrient solution for 7 days. Results are means, with $\mathrm{n}=4$. Different lower-case letters indicate statistically significant differences between $\mathrm{Mn}$ treatments for the same cultivar $(\mathrm{P}<0.05)$; while different upper-case letters indicate statistically significant differences between cultivars under the same Mn treatment. 


\subsection{Lipid peroxidation}

Oxidative damage is represented by lipid peroxidation (LP). These parameters showed a strong positive correlation to the increasing Mn content in shoots of Tatoo, Scarlett and Barke $(r=0.759 ; r=0.744, r=0.742$, respectively), indicating higher oxidative damage with an increase Mn concentration. Oppositely, roots showed no correlation between LP and Mn content when increasing doses of Mn were applied, except in Scarlett (Figure 2). Scarlett showed a significant increment of oxidative damage to shoots (above of $60 \mathrm{nmol}$ of MDA), with the highest Mn treatment compared with the other barley cultivars.

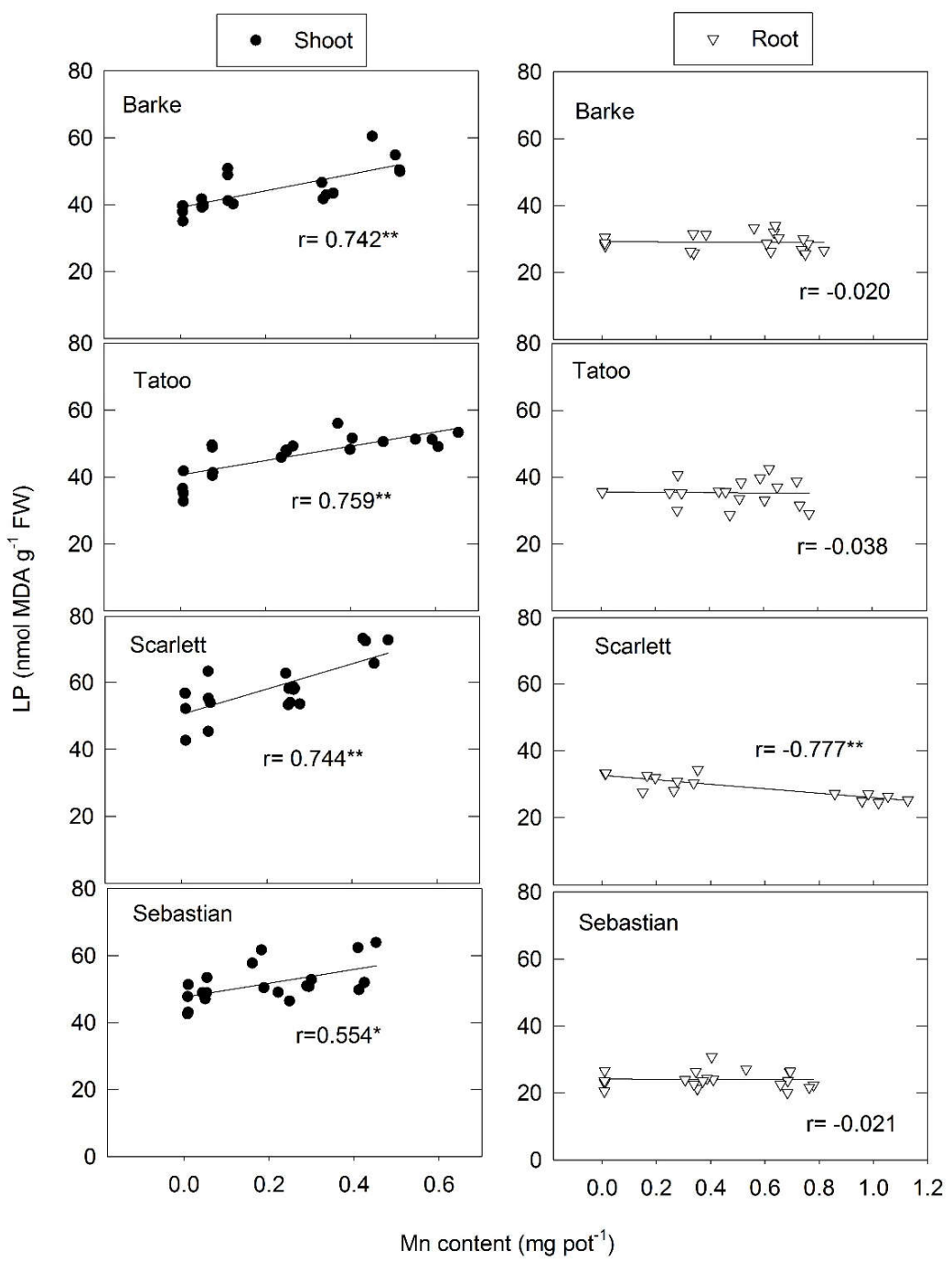

Figure 2. Shoot and root LP vs Mn content in barley cultivars subjected to Mn treatments during seven days. Black circles represent shoots, and white triangles are roots. The Pearson correlation was used to test relationships between the response variables: $* \mathrm{P}<0.05$; ** $\mathrm{P}<0.01$ 


\subsection{Antioxidant activity (AA)}

Increasing $\mathrm{Mn}$ treatments were greater in shoots than in roots for barley cultivars (Figure 3A). In barley shoots, Barke had the highest antioxidant activity values compared with the other cultivars, although it showed no differences with higher Mn doses. Tatoo increased from $350 \mu \mathrm{M}$ Mn, Sebastian decreased AA with intermediate $\mathrm{Mn}$ treatments, although there was no change with the last Mn treatment $(1500 \mu \mathrm{M}$ $\mathrm{Mn})$, compared with the control $(2.4 \mu \mathrm{M} \mathrm{Mn})$. Scarlett cultivars showed no significant changes with $\mathrm{Mn}$ treatments. In the roots, Barke, Tatoo and Scarlett remained unaltered, and in contrast, Sebastian had a significant increment with higher Mn doses (750 and $1500 \mu \mathrm{M} \mathrm{Mn}$ ) compared to the control of $2.4 \mu \mathrm{M} \mathrm{Mn}$.

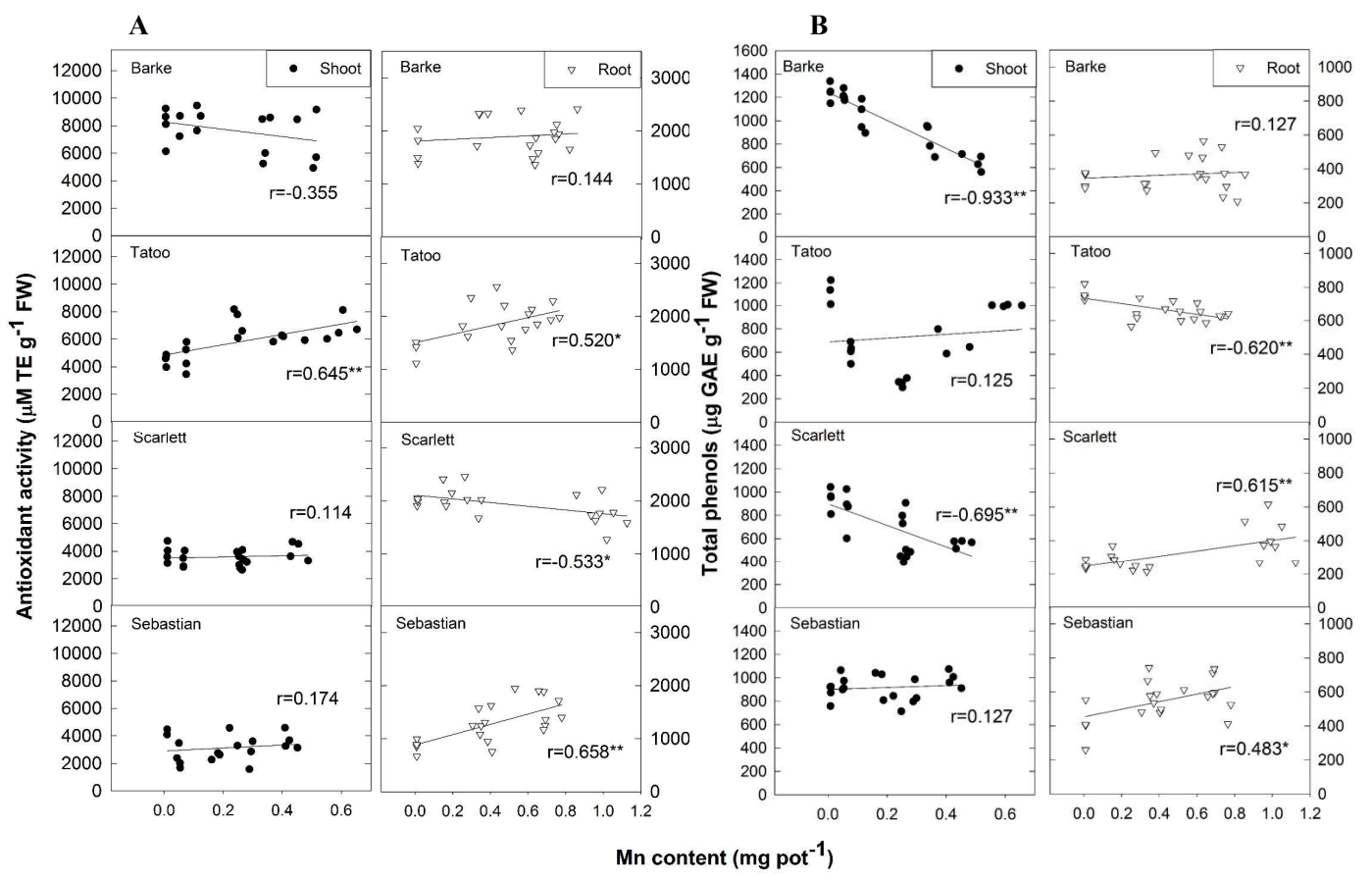

Figure 3. Antioxidant activity (A) and total phenols (B) vs Mn content in barley cultivars subjected to Mn treatments during seven days. Black circles represent shoots and white triangles are roots. The Pearson correlation was used to test relationships between the response variables: ${ }^{*} \mathrm{P}<0.05 ; * * \mathrm{P}<0.01$.

\subsection{Total phenols (TP)}

Total phenols (TP) in the shoots were higher than in roots for the barley cultivars. Barke and Scarlett significantly decreased TP with higher Mn concentrations (Figure 3B).
In the roots, there was a strong decreased of $\mathrm{TP}$ only in Tatoo $(r=0.509)$, although it increased with the highest Mn treatment, similar to control values. Scarlett and Sebastian increased TP values only at the highest Mn treatment. 


\subsection{SOD and POD activity}

Values of SOD enzyme activity in roots were higher than shoots for the barley cultivars (Figure 4A). In the roots, Tatoo showed an increase of SOD activity 1.8fold higher in the last Mn treatments, compared with

A

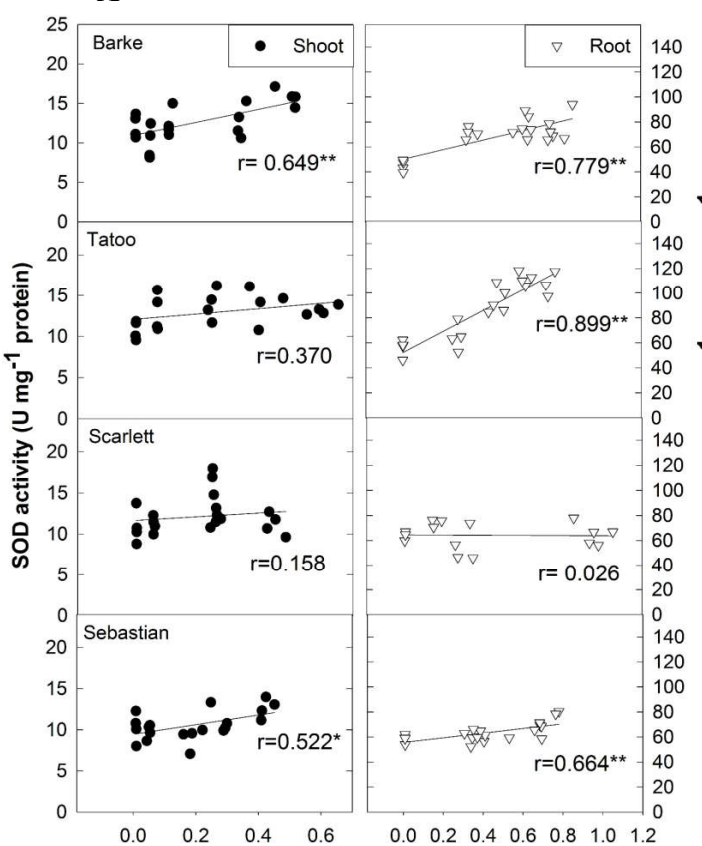

with the control. Barke increased SOD activity with all Mn treatments, and Sebastian only increased with the highest Mn dose. Nevertheless, Scarlett had a decrease of SOD activity with the intermediate Mn dose. However, there were no differences with the highest Mn treatment.

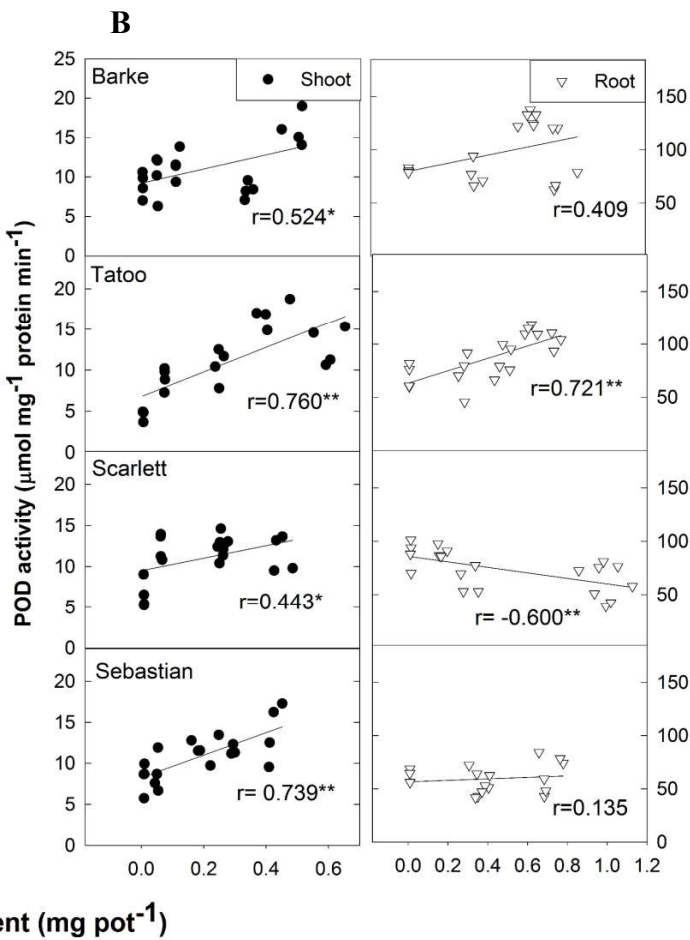

Figure 4. Superoxide dismutase (SOD) activity (A) and guaiacol peroxidase (POD) activity (B) vs Mn content in barley cultivars grown in nutrient solutions with increasing Mn doses during seven days. Dark circles represent shoots and white triangles are roots. The Pearson correlation was used to test the relationships between the response variables: $* \mathrm{P}<0.05, * * \mathrm{P}<0.01$

Likewise, POD activity also showed higher activity in roots than in shoots in the studied barley cultivars (Figure 4B). The POD activity of shoots incremented from the minimal Mn treatment applied (Tatoo and Scarlett). Barke and Sebastian had significant differences only with the highest Mn treatment, compared with the control. In roots, Tatoo increased its POD activity with the higher Mn treatments compared to the control. Scarlett and Sebastian exhibited a decrease of POD activity with the increasing Mn dose, but there were no significant differences with the $1500 \mu \mathrm{M} \mathrm{Mn}$. 
According to PCA, in the shoot samples we observed that control (green circles) were grouped independently at highest $\mathrm{Mn}$ doses $(1500 \mu \mathrm{M})$ revealing differences among treatments at distance 2.5 (Figure 5). For example, in general control samples were most related with yield parameters such as length, RGR and biomass. In contrast, treatments with the highest $\mathrm{Mn}$ doses showed more relation with antioxidant performance, i.e Scarlett and Sebastian with LP and Mn content, Tatoo with SOD and AA. In roots, we found similar behavior, where control as Sebastian, Barke and Scarlett were associated to chemical parameters but control of Tatoo showed a major relation to antioxidant activity as is the case of cultivars grown under the highest Mn doses (Figure 5).
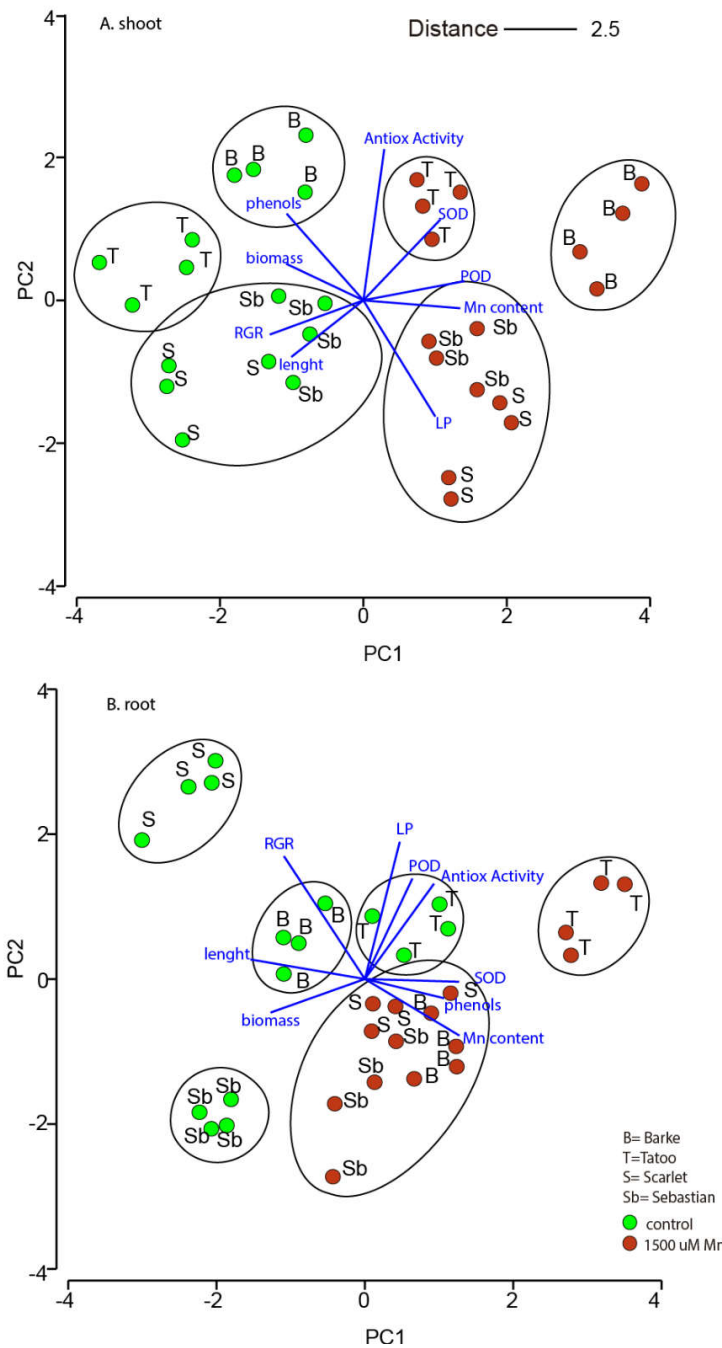

Figure 5. Principal component analysis (PCA) performed on the Euclidean distance matrix for biomass, length, antioxidant activity (AA), RGR, guaiacol peroxidase (POD), superoxide dismutase (SOD), phenols and Mn content of barley cultivars subjected to Mn treatments: Control $(2.4 \mu \mathrm{M} \mathrm{Mn})$ and $1500 \mu \mathrm{M} \mathrm{Mn}$. 


\subsection{Organic acid exudation}

Carboxylate exudates by roots were exhibited among the control plants and by the barley cultivars under the highest Mn treatment (Figure 6A). Barley oxalate exudation in Sebastian, Scarlett and Barke was significantly higher with $1500 \mu \mathrm{M}$ Mn. Contrarily, malate exudation was the highest for the control roots compared with Mn treatments for the same barley cultivars. Only Tatoo showed an increase of malate with the highest Mn dose. For citrate exudation, Tatoo and Barke displayed strong differences between the control and $1500 \mu \mathrm{M}$ Mn. Thus, during last Mn treatment, the highest values of citrate exudation were obtained. In the principal component analyses (PCA), Sebastian, which was more tolerant to elevated Mn concentrations, shower a higher production of oxalate and succinate compared with the rest of cultivars. Scarlett also showed major production of succinate, and given that oxalate and succinate exudation was similar between, both Sebastian and Scarlett were grouped in the same cluster. Scarlett was affected with increasing doses of $\mathrm{Mn}$. Control samples were related with malate exudation, whereas Barke and Tatoo with citrate exudation (Figure 6B). 


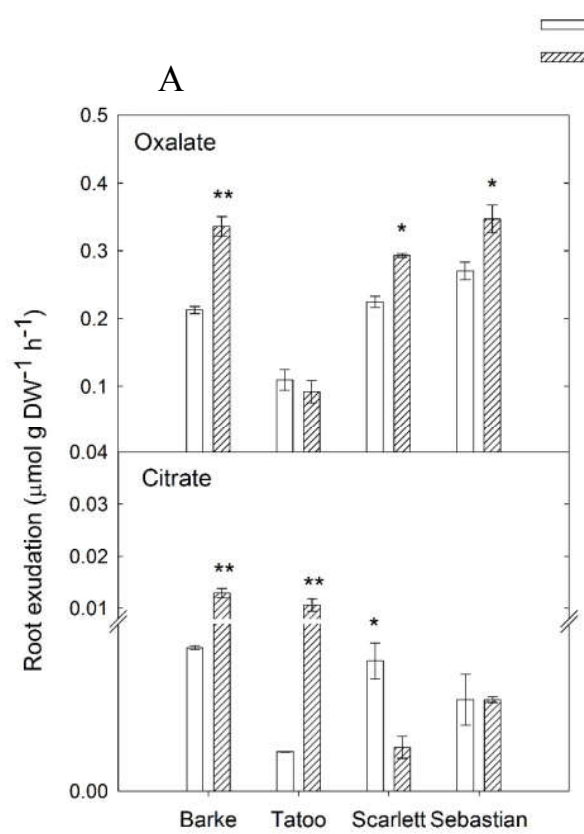

$2.4 \mu \mathrm{M}$

mams $1500 \mu \mathrm{M}$

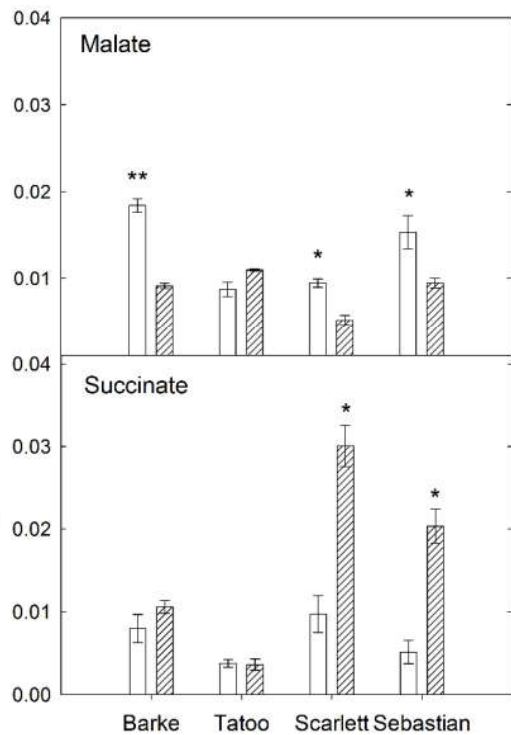

B

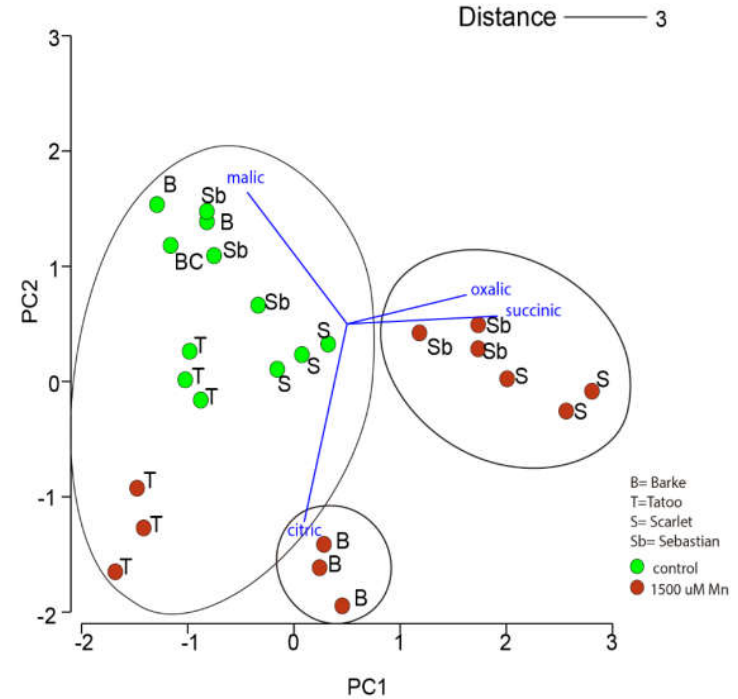

Figure 6. A: Carboxylates (organic anions) exuded by roots of barley cultivars during $7 \mathrm{~d}$ grown in nutrient solution exposed to: Control $(2.4 \mu \mathrm{M} \mathrm{Mn})$ and the highest Mn doses (1500 $\mu \mathrm{M} \mathrm{Mn})$. The independent sample t-test was used to determine significant differences between $\mathrm{Mn}$ treatments for the same cereal cultivar and carboxylates: ${ }^{*} \mathrm{P}<0.05$, ** $\mathrm{P}<0.01$ B: Principal component analysis (PCA) performed on the Euclidean distance matrix for the citric, succinic, and oxalic acid carboxylate exudates from barley cultivars subjected to Mn treatments: Control (green circles) $2.4 \mu \mathrm{M} \mathrm{Mn}$ and $1500 \mu \mathrm{M} \mathrm{Mn}$ (red circles). 


\section{Discussion}

In Chilean volcanic soil, cereal production is limited by a combination of low available $\mathrm{P}$, low $\mathrm{pH}$ and high concentrations of toxic aluminum $\left(\mathrm{Al}^{3+}\right)$ and manganese $\left(\mathrm{Mn}^{2+}\right)$ (Mora et al., 2009). Excess $\mathrm{Mn}^{2+}$ in soil can be readily transported into the root cells and translocate to the shoots, causing a negative effect on crop productivity (Marschner and Marschner, 2012). In this study, we determined the early responses to excess Mn in four commercial barley cultivars (Barke, Tatoo, Scarlett and Sebastian). We found that Mn content was higher in roots than in shoots, and proportional to increasing Mn treatments in all cultivars. This finding is similar to that reported by Rosas et al., (2007) and Inostroza-Blancheteau et al., (2017) in ryegrass from Chilean Andisol. In contrast, recent studies in maize (Silva et al., 2017) and barley genotypes (Huang et al., 2015) showed that some Mn-tolerant genotypes exhibited higher Mn concentrations in shoots than in roots due to internal tolerance mechanisms.

In general, Tatoo and Sebastian showed similar biomass parameters when grown at high Mn content; whereas Barke and Scalett decreased their biomass parameters, as was reported for Mn-barley sensitive cultivars (Mora et al., 2009; Ribera et al., 2013). Despite previous studies showing that lipid peroxidation (LP) is an important indicator to metal toxicity in ryegrass (Mora et al., 2009; Inostroza-Blancheteau et al., 2017), cucumber (Shi et al., 2005) and maize (Srivastava and Dubey 2011), we observed only an increase of LP in shoot of all cultivars. In contrast, antioxidant performance was given by antioxidant enzymes, where mainly SOD activity was activated. Thus, Barke, Tatoo and Sebastian showed higher SOD production in roots at increasing Mn doses. This mechanism could be involved in tolerance against oxidative stress, to convert superoxide radicals into hydrogen peroxide and water, playing a principal role in the defense against excess $\mathrm{Mn}$ in tolerant plants (Sharma et al., 2012; Silva et al., 2017). Meanwhile, POD increased in the shoots of all cultivars. Demirevska-Kepova et al., (2004) showed that apoplastic POD activity in barley is strongly associated to brown spots on leaves at increasing Mn content. Our results showed that brown spots on shoots and necrotic roots were evidenced at higher Mn treatments (Figure 7). Interestingly, antioxidant activity (AA) in tolerant cultivars of Tatoo and Sebastian was increased at high Mn doses, whereas total phenols (TP) were decreased in shoots of Barke and Scarlett. This is in concordance with Ribera-Fonseca et al., (2013) in ryegrass, suggesting that AA and TP play a role in radical scavenging ability. However, no clear tendency in TP production was observed in this study.

Regarding organic acid production in roots, we found that tolerant Sebastian cultivars showed high oxalate production, similar to sensitive Barke and Scarlett. Several studies showed that oxalate is related to sequestration of soluble $\mathrm{Mn}$ in woody plants and legume species, decreasing $\mathrm{Mn}^{2+}$ free ions in soil (Liu et al. 2017). This is similar to that reported about microorganisms associated barley plant roots grown in acidic Andisol (Mora et al., 2017).

In summary, Tatoo and Sebastian were tolerant to high Mn doses, whereas Barke and Scarlett were sensitive. Also, higher oxalate exudation was found in Sebastian, supporting that it is a Mn-tolerant cultivar. Furthermore, Tatoo and Sebastian cultivars showed a tolerant early response against Mn stress, which could increase for longer periods under field conditions. 


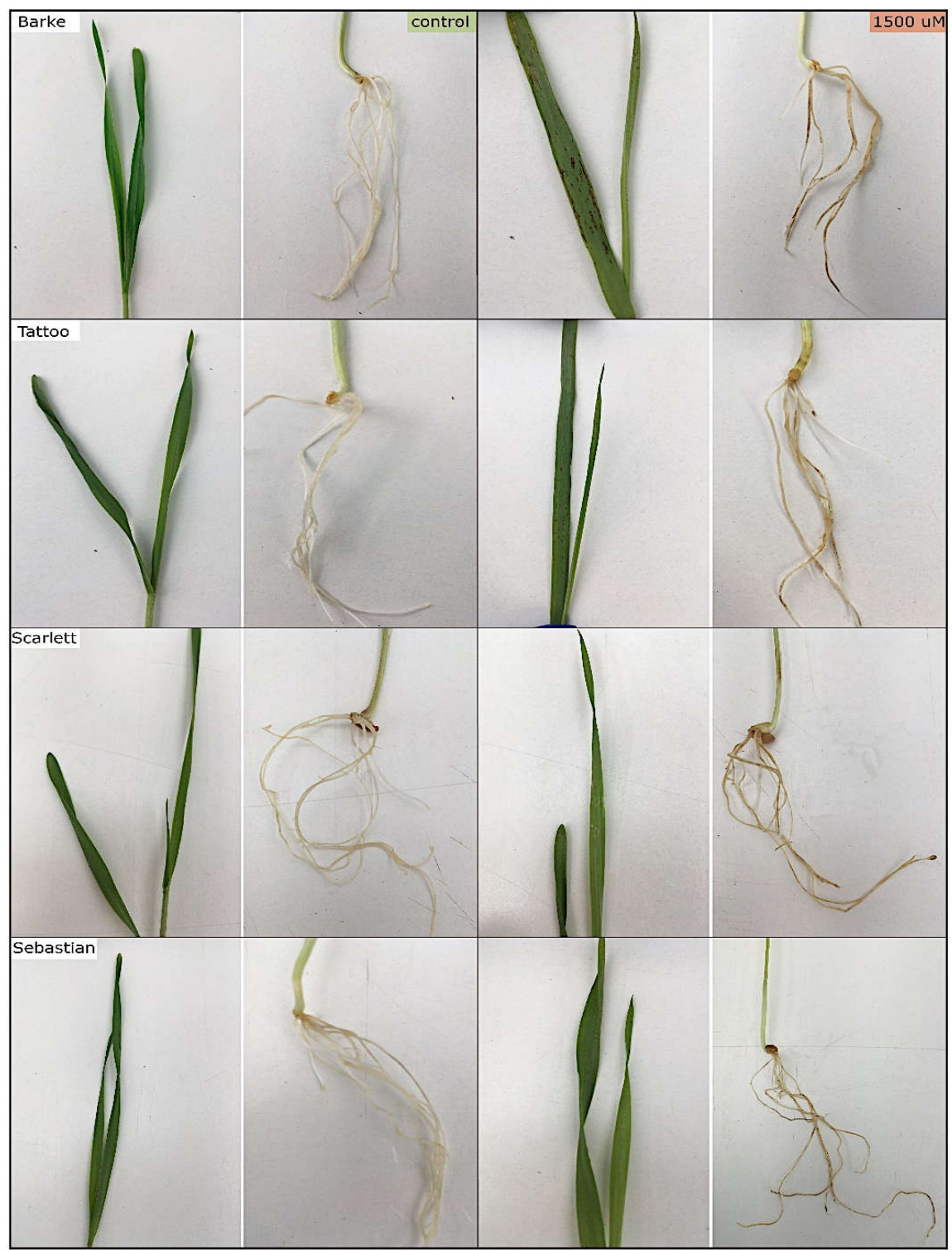

Figure 7. Visual symptoms of Mn excess in leaves (brown spots) and roots (necrotic tissues) at $1500 \mu \mathrm{M}$ (right) compared with control samples (left) of barley plants (Barke, Tatoo, Scarlett and Sebastian). 


\section{Conclusion}

We determined the early responses to excess $\mathrm{Mn}$ in four barley cultivars (Barke, Tatoo, Scarlett, Sebastian). Tatoo and Sebastian are proposed as Mn tolerant given that the biomass parameters were not affected by increasing Mn doses. The mechanisms associated to Mn alleviation could be attributed to SOD, AA and organic acid production, mainly oxalate with a concomitant diminution of total phenols in shoot of sensitive cultivars (Barke and Scarlett). Non-enzymatic barriers were not related to early responses, and only an enzymatic barrier and oxalate exudation were considered as early indicators of Mn stress. Further studies are needed to elucidate these plant effects under field conditions, as well as genetic mechanisms involved in Mn tolerance.

\section{Acknowledgements}

This research was financially supported by the Comisión Nacional de Investigación Científica y Tecnológica (CONICYT) from the Chilean Government through the FONDECYT Postdoctoral Project $\mathrm{N}^{\circ}$ 3160799. The authors greatly appreciate the access to equipment and infrastructure facilities granted by the Scientific and Technological Bio-resource Nucleus at the Universidad de La Frontera (BIOREN-UFRO). Finally, we wish to thank Pamela Morales Muñoz for her valuable laboratory assistance.

\section{References}

Bityutskii, N., Yakkonen, K., Petrova, A., Nadporozhskaya, M. 2017. Xylem sap mineral analyses as a rapid method for estimation plant-availability of $\mathrm{Fe}, \mathrm{Zn}$ and $\mathrm{Mn}$ in carbonate soils: a case study in cucumber. J. Soil Sci. Plant Nutr. 17, 279-290.
Blamey, P., Hernandez-Soriano, M., Cheng, M., Tang, C., Paterson, D.J., Lombi E., Wang, W.H., Scheckel, K.G., Kopittke, P.M. 2015. Synchrotron-based techniques shed light on mechanisms of plant sensitivity and tolerance to high manganese in the root environment. Plant Physiol. 169, 2006-2020.

Chinnici, F., Bendini, A., Gaiani, A., Riponi, C. 2004. Radical scavenging activities of peels and pulps from $\mathrm{cv}$. golden delicious apples as related to their phenolic composition. J. Agric. Food Chem. 52, 4684-4689.

Demirevska-Kepova, K., Simova-Stoilova, L., Stoyanova, Z., Hölzer, R., Feller, U. 2004. Biochemical changes in barley plants after excessive supply of copper and manganese. Environ. Exp. Bot. 52, 253-266.

Du, Z., Bramlage, W. 1992. Modified thiobarbituric acid assay for measuring lipid oxidation in sugarrich plant tissue extracts. J. Agric. Food Chem. 40, 1566-1570.

Fernando, D.R., Baker, A.J.M., Woodrow, I.E. 2009. Physiological responses in Macadamia integrifolia on exposure to manganese treatment. Aust. J. Bot. 57, 406-413.

Gangwar, S., Singh, V.P., Prasad, S.M., Maurya, J.N. 2010. Modulation of manganese toxicity in Pisum sativum L. seedlings by kinetin. Sci. Hortic. (Amsterdam). 126, 467-474.

Hodges, D., DeLong, J., Forney, C., Prange, R. 1999. Improving the thiobarbituric acid-reactive-substances assay for estimating lipid peroxidation in plant tissues containing anthocyanin and other interfering compounds. Planta. 207, 604-611.

Huang, X., Shabala, S., Shabala, L., Rengel, Z., Wu, X., Zhang, G., Zhou, M. 2015. Linking waterlogging tolerance with $\mathrm{Mn}^{2+}$ toxicity: A case study for barley. Plant Biol. 17, 26-33. 
Inostroza-Blancheteau, C., Reyes-Díaz, M., Berríos, G., Rodrigues-Salvador, A., Nunes-Nesi, A., Deppe, M., Demanet, R., Rengel, Z., Alberdi, M. 2017. Physiological and biochemical responses to manganese toxicity in ryegrass (Lolium perenne L.) genotypes. Plant Physiol. Biochem. 113, 89-97.

Jones, D.L., Darrah, P.R. 1994. Role of root derived organic acids in the mobilization of nutrients from the rhizosphere. Plant Soil. 166, 247-257.

Kopittke, P.M., Lombi, E., McKenna, B.A., Wang, P., Donner, E., Webb, R.I., Blamey, F.P.C., de Jonge, M.D., Paterson, D., Howard, D.L., Menzies, N.W. 2013. Distribution and speciation of Mn in hydrated roots of cowpea at levels inhibiting root growth. Physiol. Plant. 147, 453-464.

Li, P., Song, A., Li, Z., Fan, F., Liang, Y. 2012. Silicon ameliorates manganese toxicity by regulating manganese transport and antioxidant reactions in rice (Oryza sativa L.). Plant Soil. 354, 407-419.

Liu, Y., Li, Z., Xu, R. 2017. The distribution of Mn (II) chemical forms on soybean roots as related to Mn (II) toxicity. Pedosphere. (In press). https:// doi.org/10.1016/S1002-0160(17)60413-2

Marschner, H., Marschner, P. 2012. Marschner's mineral nutrition of higher plants. Academic Press. $651 \mathrm{p}$.

Meier, S., Alvear, M., Borie, F., Aguilera, P., Ginocchio, R., Cornejo, P. 2012. Influence of copper on root exudate patterns in some metallophytes and agricultural plants. Ecotoxicol. Environ. Saf. 75, $8-15$.

Millaleo, R, Reyes- Diaz, M., Ivanov, A., Mora, M.L., Alberdi, M. 2010. Manganese as essential and toxic element for plants: Transport, accumulation and resistance mechanisms. J. Soil Sci. Plant Nutr. $10,470-481$.

Mora, M.L., Rosas, A., Ribera, A., Rengel, Z. 2009. Differential tolerance to $\mathrm{Mn}$ toxicity in perennial ryegrass genotypes: Involvement of antioxidative enzymes and root exudation of carboxylates. Plant Soil. 320, 79-89.

ODEPA, 2018. Boletín de cereales. Departamento de información agraria, Oficina de estudios y políticas agrarias, Ministerio de Agricultura, Gobierno de Chile. Santiago, Chile, 63p.

Reyes-Díaz, M., Inostroza-Blancheteau, C., Berríos, G., Deppe, M., Demanet, R., Alberdi M. 2017. Physiological traits and Mn transporter genes expression in ryegrass genotypes under increasing Mn at short-term. Plant Physiol. Biochem. 118, 218-227.

Ribera, A.E., Reyes-Díaz, M.M., Alberdi, M.R., Alvarez-Cortez, D.A., Rengel, Z., Mora, M.L. 2013. Photosynthetic impairment caused by manganese toxicity and associated antioxidative responses in perennial ryegrass. Crop Pasture Sci. 64, 696-707.

Rosas, A., Rengel, Z., Mora, M.L. 2007. Manganese supply and $\mathrm{pH}$ influence growth, carboxylate exudation and peroxidase activity of ryegrass and white clover. J. Plant Nutr. 30, 253-270.

Sadzawka, A., Carrasco, M., Demanet, R., Flores, H., Grez, R., Mora, M.L., Neaman, A. 2007. Métodos de análisis de tejidos vegetales. Instituto de Investigaciones Agropecuarias, Serie Actas INIA $\mathrm{N}^{\circ} 40$, Santiago, Chile. $140 \mathrm{p}$.

Santos, E.F., Kondo Santini, J.M., Paixão, A.P., Júnior, E.F., Lavres, J., Campos, M., dos Reis, A.R. 2017. Physiological highlights of manganese toxicity symptoms in soybean plants: Mn toxicity responses. Plant Physiol. Biochem. 113, 6-19.

Shao, J.F., Yamaji, N., Shen, R.F., Ma, J.F. 2017. The key to Mn homeostasis in plants: Regulation of Mn transporters. Trends Plant Sci. 22, 215-224.

Sharma, P., Jha, A.B., Dubey, R.S., Pessarakli, M. 2012. Reactive oxygen species, oxidative damage, and antioxidative defense mechanism in plants under stressful conditions. J. Bot. 2012, $1-26$. 
Shi, Q., Bao, Z., Zhu, Z., He, Y., Qian, Q., Yu, J. 2005. Silicon-mediated alleviation of Mn toxicity in Cucumis sativus in relation to activities of superoxide dismutase and ascorbate peroxidase. Phytochemistry. 66, 1551-1559.

Shi Q, Zhu Z, Xu M, Qian, Q., Yu, J. 2006. Effect of excess manganese on the antioxidant system in Cucumis sativus L. under two light intensities. Environ. Exp. Bot. 58,197-205.

Silva, D.M., Fonte, N.D.S., Souza, K.R.D., Rodrigues-Brandão, I., Libeck, I.T., Alves, J.D. 2017. Relationship between manganese toxicity and waterlogging tolerance in Zea mays L. cv. Saracura. Acta Sci. Agron. 39,75-82.

Srivastava, S., Dubey, R.S. 2011. Manganese-excess induces oxidative stress, lowers the pool of antioxidants and elevates activities of key antioxidative enzymes in rice seedlings. Plant Growth Regul. 64, 1-16.
St.Clair, S.B., Lynch, J.P. 2005. Element accumulation patterns of deciduous and evergreen tree seedlings on acid soils: Implications for sensitivity to manganese toxicity. Tree Physiol. 25, 85-92.

Taylor, G.J., Foy, C.D. 1985. Mechanisms of Aluminum tolerance in Triticum aestivum L. (wheat). II. Differential $\mathrm{pH}$ induced by spring cultivars in nutrient solutions. Am. J. Bot. 72, 702-706.

Ulloa-Inostroza, E.M., Alberdi, M., Meriño-Gergichevich, C., Reyes-Díaz, M. 2017. Low doses of exogenous methyl jasmonate applied simultaneously with toxic aluminum improve the antioxidant performance of Vaccinium corymbosum. Plant Soil. 412, 81-96. 